\title{
Ornidazole: A new antiprotozoal compound for treatment of Trichomonas vaginalis infection
}

\author{
MARIANNE SKÖLD, HÅKAN GNARPE, AND LARS HILLSTRÖM \\ From the Department of Dermatology and Venereology and the Department of Medical Microbiology, \\ District General Hospital, Gävle, Sweden
}

SUMMARY A new anti-protozoal compound, ornidazole ${ }^{\mathfrak{1}}$, a derivative of nitroimidazole, was given in a single $2 \mathrm{~g}$ dose to 20 women with Trichomonas vaginalis infection. All the women were cured, but they suffered some side-effects. Plasma levels of ornidazole reached a peak five to eight times higher than minimum inhibitory concentrations and exceeded this level for at least 36 hours. It is therefore possible that a smaller dose might have had an adequate trichomonicidal effect and fewer side-effects. Further studies are in progress.

\section{Introduction}

Since its introduction in 1959 , metronidazole, a nitroimidazole derivative, has been the drug of choice for treatment of Trichomonas vaginalis infections. It has usually been given in multiple doses and failures have generally been due to incomplete treatment, either of the patients and/or the partners.

Ornidazole is a recently synthetised nitroimidazole derivative (Fig. 1) and the first clinical trials have shown excellent results-that is, a $100 \%$ cure rate with different dosages and even with a single $2 \mathrm{~g}$ dose (Warnnissorn, 1974).<smiles>Cc1ncc([N+](=O)[O-])n1CCOCCl</smiles><smiles>Cc1ncc([N+](=O)[O-])n1CCO</smiles>

Fig. 1

Ornidazole

1-(3-chloro-2-hydroxypropyl)-2-methyl-5nitroimidazole

Metronidazole 1-(2-hydroxietyl)-2methyl-5-nitroimidazole

To collect more data on ornidazole we made the following investigations:

- a study of the effect and tolerance of ornidazole when given as a single $2 \mathrm{~g}$ dose for $T$. vaginalis infection

Address for reprints: M. Sköld, Department of Dermatology and Venereology, District General Hospital, Fack, S-800 07 Gävle 7, Sweden

Received for publication 23 March 1976 -a laboratory examination of minimum inhibitory concentrations of ornidazole on $T$. vaginalis strains isolated from these patients

- a comparison of minimum inhibitory concentrations of ornidazole with those of metronidazole, nitrimidazine, and tinidazole on $T$. vaginalis strains isolated from clinical material

- a determination of plasma levels of unchanged ornidazole after oral administration of a $2 \mathrm{~g}$ dose.

Material and methods

EFFECT AND TOLERANCE STUDY

The clinical study was performed on 20 women outpatients aged between 15 and 36 years, with $T$. vaginalis infection. Subjective symptoms had been present for between two weeks and three years, except in eight who had no symptoms. The patients were selected because they were otherwise healthy, not pregnant, and were willing to return for further examination.

Ten of the patients had been treated with ampicillin for gonococcal infections at least three days before the study; seven women used contraceptive pills. No other medication was used. The patients were instructed to take $2 \mathrm{~g}$ of ornidazole just before going to bed (one of the side-effects noted in previous trials had been somnolence, Warnnissorn, 1974). This dose corresponded to 24 to $40 \mathrm{mg} / \mathrm{kg}$ body weight.

To prevent re-infection, partners were treated in

${ }^{1}$ Ro 7-0207, Tiberal, Kolpicid, F. Hoffmann-La Roche \& Co Ltd, Basel 
the same way as the patients, but were not included in the study.

The patients were examined just before treatment and then five days and one month after they had been treated. The following procedures were performed on each occasion:

- subjective symptoms - such as, itching, smarting pain and/or increased discharge-were recorded

-objective signs were noted. Of these, increased redness of the vaginal mucosa with or without increased discharge was considered to be the main criterion of vaginal infection

- specimens were collected for $T$. vaginalis culture (see laboratory diagnosis). This procedure would also reveal the presence of Candida albicans

- smears from the cervix were stained with methylene blue and examined microscopically for polymorphonuclear leucocytes (PMN) and intracellular diplococci. An average of 10 or more PMN seen in more than three highpower fields $(\times 1000)$ were recorded as 'leucocytic reaction' (Wallin et al., 1974)

- Haemoglobin concentration, total and differential leucocyte count, thrombocytes, serum aspartate aminotransferase, serum alanine aminotransferase, alkaline phosphatase, and serum creatinine levels were determined using standard techniques.

\section{LABORATORY DIAGNOSIS}

Specimens were taken from the cervix with a sterile cotton swab which was immediately inserted into a modified Stuart's transport medium (Securline, MH 102, Cameco, Enebyberg, Sweden) and then sent to the bacteriological laboratory where specimens were inoculated into Diamond's medium and incubated at a temperature of $37^{\circ} \mathrm{C}$. Wet preparations were examined daily by dark-field illumination. If no growth had appeared within one week, specimens were discarded as negative. According to Wallin et al. (1974), this is a better method than direct microscopical examination.

\section{DETERMINATION OF MINIMUM INHIBITORY CONCENTRATION}

Positive cultures were re-inoculated into fresh, prewarmed Diamond's medium which was incubated overnight. The cultures were then diluted 1 in 10 in Diamond's medium and $0.10 \mathrm{ml}$ volumes of this suspension were inoculated into a series of $5 \mathrm{ml}$ volumes of Diamond's medium containing concentrations of ornidazole decreasing in two-step

${ }^{1}$ These determinations were performed by Dr D. E. Schwartz, Department of Experimental Medicine, F. Hoffmann-La Roche \& Co Ltd, Basel dilutions from $20 \mu \mathrm{g} / \mathrm{ml}$ to $0.08 \mu \mathrm{g} / \mathrm{ml}$. Altogether 18 of the trichomonas strains isolated, and an additional 13 strains from other patients not in the study, were treated in this way. Minimum inhibitory concentration values for nimorazole (Naxogin ${ }^{\circledR}$ ), metronidazole (Flagyl ${ }^{\circledR}$, Elyzol ${ }^{\circledR}$ ) and tinidazole (Fasigyn ${ }^{\circledR}$ ) were also estimated using the 13 strains.

The influence of these drugs on the normal serum bactericidal effect was determined according to Forsgren and Gnarpe (1973). Serum specimens were obtained from five healthy women. The respective drugs were added to the serum specimens in two different concentrations, 40 and $10 \mu \mathrm{g} / \mathrm{ml}$. The same strain (Escherichia coli $\operatorname{Tr} 1$ ) as in earlier studies was again used.

\section{PHARMACO-KINETIC STUDY}

Five healthy female volunteers, aged between 24 and 45 years, were given $2 \mathrm{~g}$ ornidazole (corresponding to $28-39 \mathrm{mg} / \mathrm{kg}$ body weight) after a light breakfast without fat. Serial samples of $10 \mathrm{ml}$ of blood were taken before and 2-72 hours after administration. Plasma was separated within one hour, immediately frozen and sent to Basel ${ }^{1}$ for analysis of unchanged ornidazole in plasma by thin-layer chromatography (Hezel, 1973).

\section{Results}

The results of the clinical study are shown in Table 1 . All 20 women attended the first follow-up, and 19 of these returned a month later. All cultures were negative after treatment although one of the patients still had a discharge. Of the eight symptomless patients at the beginning of the study, two noticed reduction of their usual discharge after treatment.

Table 1 Results before and after treatment of $\mathrm{T}$. vaginalis infection with ornidazole in a single dose of $2 \mathrm{~g}$. Figures represent number of patients

\begin{tabular}{|c|c|c|c|}
\hline & \multirow{2}{*}{$\begin{array}{l}\text { Before treatment } \\
(n=20)\end{array}$} & \multicolumn{2}{|c|}{ After treatment } \\
\hline & & $\begin{array}{l}5-8 \text { days } \\
\left(n=20^{*}\right)\end{array}$ & $\begin{array}{l}\text { One month } \\
(n=19+)\end{array}$ \\
\hline \multicolumn{4}{|l|}{ Positive $T$. vaginalis } \\
\hline Objective signs & 10 & 7 & 2 \\
\hline Subjective symptoms & 12 & 2 & 1 \\
\hline
\end{tabular}

* No clinical evaluation of one patient because of menstruation tOne patient did not attend the last follow-up

Eight patients complained of side-effects at the first follow-up visit, Table 2 . These were not related to dose/kg body weight. Sixteen patients had leucocytic reaction before treatment and this was still present in 14 of them at the last visit. (This particular examination was inadvertently omitted on the other two patients.) 


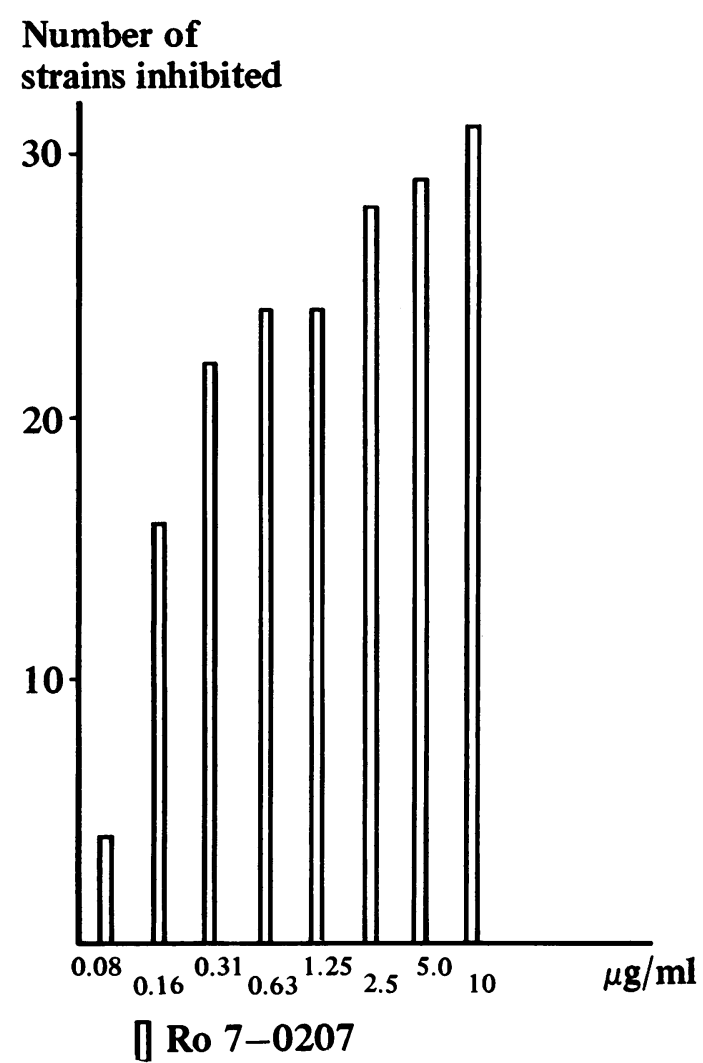

Fig. 2 Minimum inhibitory concentrations of ornidazole for 31 strains of $\mathrm{T}$. vaginalis.
Table 2 Side-effects after drug administration

\begin{tabular}{lccccc}
\hline Side-effects & \multicolumn{3}{l}{ Hours } & & \\
\cline { 2 - 5 } & $1 / 2$ & 1 & 2 & $8^{*}$ & $\Sigma$ \\
\hline Fatigue and dizziness & 1 & - & 1 & - & 2 \\
Fatigue & - & 1 & - & 1 & 2 \\
Muscle pain & -1 & 1 & - & - & 2 \\
Nausea & 1 & - & - & - & 1 \\
Euphoria & 3 & 2 & 1 & 2 & 8 \\
Total & & & & & \\
\hline
\end{tabular}

*After one night's sleep

No intracellular diplococci could be demonstrated and $C$. albicans was not isolated from any culture. Haematological and biochemical parameters before and after treatment showed no change that could be related to the treatment. The minimum inhibitory concentrations of ornidazole are shown in Fig. 2. Two isolates were inhibited by $10 \mu \mathrm{g} / \mathrm{ml}$ only; 24 were inhibited by $0.63 \mu \mathrm{g} / \mathrm{ml}$. Four strains were inhibited by $0.08 \mu \mathrm{g} / \mathrm{ml}$. The minimum inhibitory concentration values of ornidazole, tinidazole, metronidazole, and nitrimidazine for the $13 T$. vaginalis strains are shown in Fig. 3 . All isolates were inhibited by $5.0 \mu \mathrm{g} / \mathrm{ml}$ of each drug. Nine strains were inhibited by $0.63 \mu \mathrm{g} / \mathrm{ml}$ of ornidazole, which is about the same result as for nitrimidazine, tinidazole, and metronidazole.

The influence of the four investigated drugs on the normal serum bactericidal effect is shown in Fig. 4 for one individual. As can be seen neither 10 nor $40 \mu \mathrm{g} / \mathrm{ml}$ of any drug reduced the serum bactericidal

\section{Number of \\ strains inhibited}

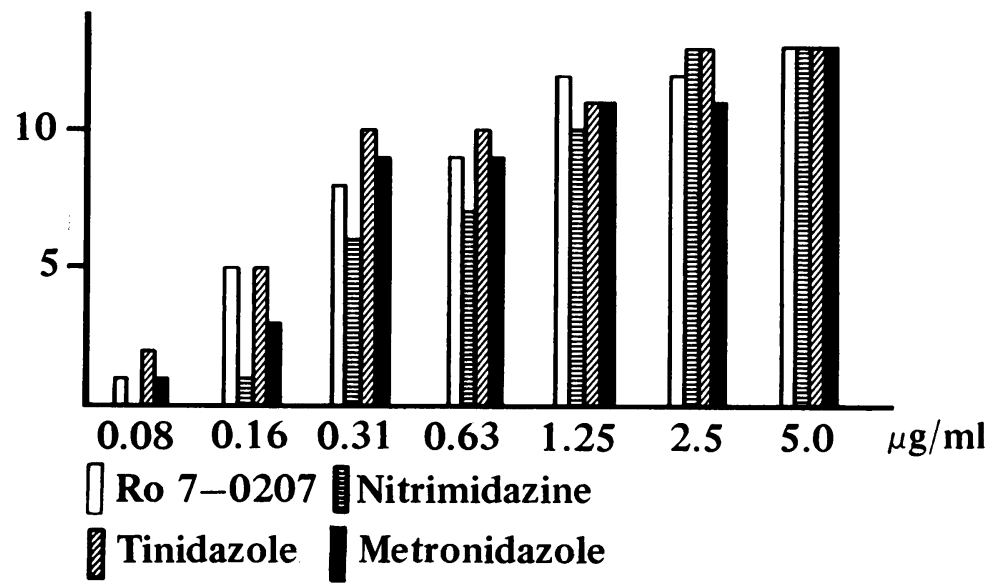

Fig. 3 Minimum inhibitory concentration values of ornidazole, tinidazole, metronidazole, and nitrimidazine for 13 strains of $\mathrm{T}$. vaginalis. 


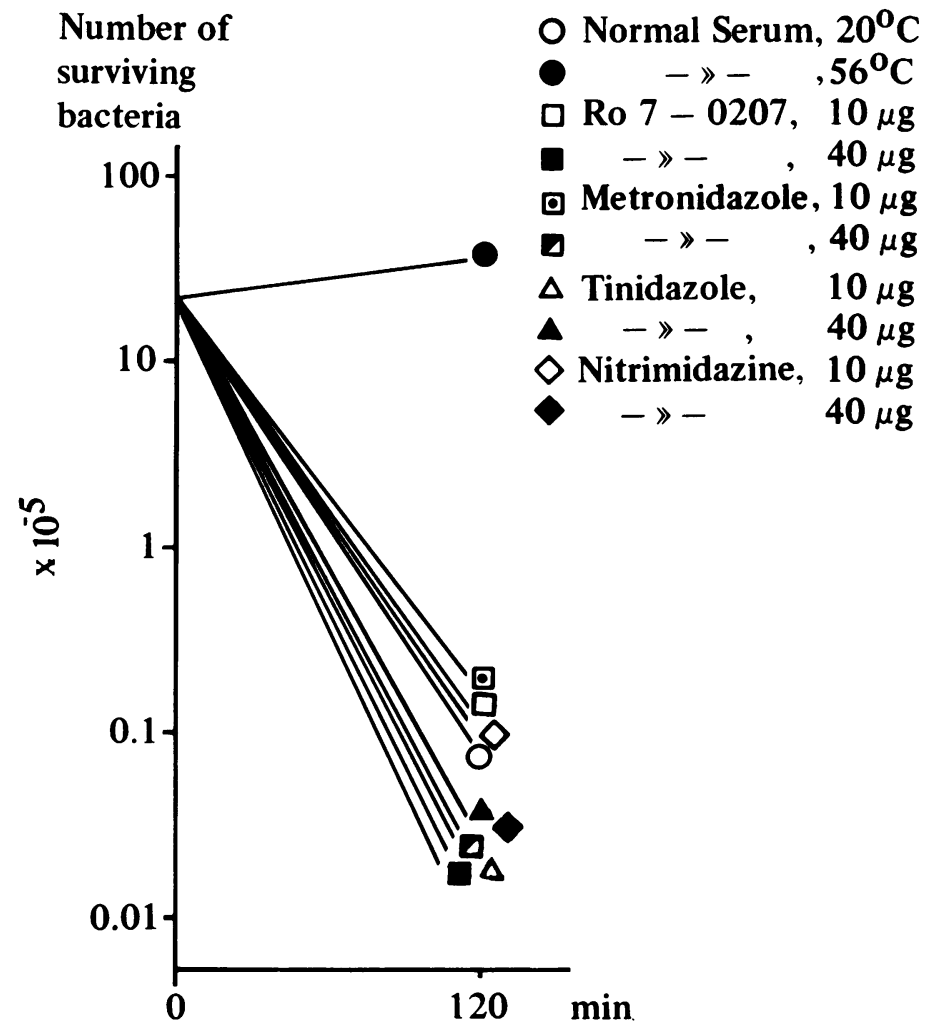

Fig. 4 Influence of ornidazole, tinidazole, metronidazole and nitrimidazine on the normal serum bactericidal effect.

effect. All investigated sera gave almost identical results.

The plasma peak-level of unchanged ornidazole was reached within two and four hours after administration and varied between 26.6 and $42 \cdot 2 \mu \mathrm{g} /$ $\mathrm{ml}$, mean value $36.8 \mu \mathrm{g} / \mathrm{ml}$, \pm 6.0 (Fig. 5). The mean half-life was determined as $12 \cdot 6$ hours \pm 1.1 .

\section{Discussion}

Judged clinically and by the negative cultures of $T$. vaginalis a single $2 \mathrm{~g}$ dose of ornidazole was successful in curing infection in all 20 patients treated. Nevertheless leucocytic reaction persisted in 14 out of 16 patients who had showed this feature before treatment.

Wallin (1974) suggested that leucocytic reaction of the cervical smear was related to infections caused by Neisseria gonorrhoeae and $T$. vaginalis. Our impression is, however, that this is a very unspecific reaction probably also indicating other pathogenic agents-for example, those causing post-gonococcal urethritis and non-gonococcal urethritis. It may also be a physiological finding in many women.

Eight women complained of side-effects, fatigue and dizziness being the most common. Since the peak of plasma levels of ornidazole was found to be between five and eight times greater than the minimum inhibitory concentration for trichomonads

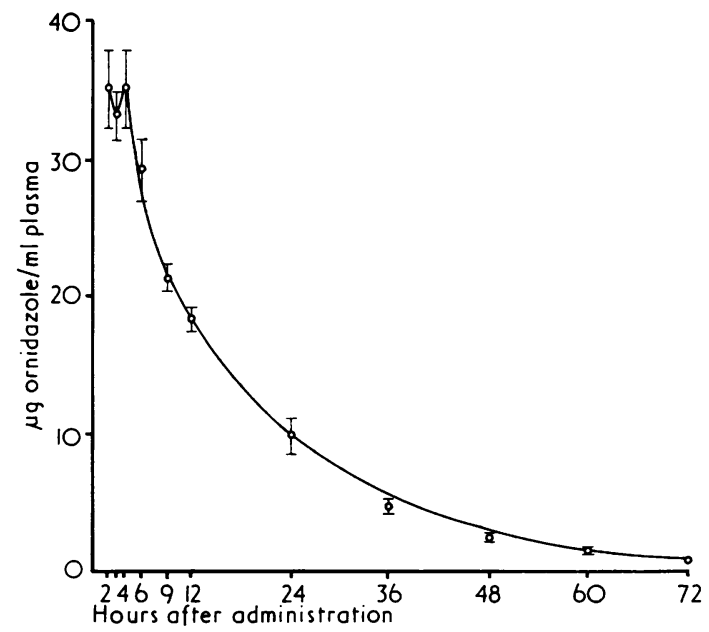

Fig. 5 Mean plasma concentrations and SEM of ornidazole in five healthy female volunteers after a $2 \mathrm{~g}$ single dose. 
and these levels were still high 36 hours after ingestion, it may be possible to give a smaller dose of ornidazole with a maintained trichomonicidal effect but fewer side-effects. Further studies are in progress.

In our study the minimum inhibitory concentration value of ornidazole does not diverge much from that of other nitroimidazole derivatives on the 13 strains examined.

The clinical results of this study compare favourably with other nitroimidazole derivatives investigated, also given in a single dose of $2 \mathrm{~g}$. For example, Csonka (1971) found a success rate of $94 \%$ using metronidazole although of the same compound, while Woodcock (1972) obtained only $85 \%$. Rösemann and Vaughan (1973) and Wallin and Forsgren (1974) using tinidazole obtained cure rates of $90 \%$ (31 patients) and 96\% (47 patients) respectively. With ornidazole Warnnissorn (1974) achieved $100 \%$ cure ( 36 patients), the same as in our series.

Thus, in conclusion ornidazole appears to have great promise as a trichomonicidal drug. However, more clinical studies are necessary, especially with regard to lessening the side-effects.

\section{References}

Csonka, G. W. (1971). Trichomonal vaginitis treated with one dose of metronidazole. British Journal of Venereal Diseases, 47, 456-458.

Forsgren, A., and Gnarpe, H. (1973). Tetracyclines and host-defense mechanisms. Antimicrobial Agents and Chemotherapy, 3, 711-715.

Hezel, U. (1973). Direkte quantitative Photometrie an DünnschichtChromatogrammen. Angewandte Chemie, 85, 334-342,

Rösemann, G. W., and Vaughan, J. (1973). Treatment of trichomoniasis in the female with a single dose of tinidazole. South African Medical Journal, 47, 1222-1224.

Wallin, J. (1974). A clinical pattern for making an immediatepresumptive diagnosis of gonococcal infection in women. Acta dermato-venereologica, 54, 157-160.

Wallin, J., and Forsgren, A. (1974). Tinidazole-a new preparation for $T$. vaginalis infections. II. Clinical evaluation of treatment with a single oral dose. British Journal of Venereal Diseases, 50, 148-150.

Wallin, J., Gnarpe, H., and Forsgren, A. (1974). Sexually transmitted diseases in women. British Journal of Venereal Diseases, 50, 217-221.

Warnnissorn, T. (1974). Single dose oral therapy $(2 \mathrm{~g})$ with Tiberal in vaginal trichomonas infection. 13th Seameo-Tropmed Seminar, Saigon, 17-21 June.

Woodcock, K. R. (1972). Treatment of trichomonal vaginitis with a single oral dose of metronidazole. British Journal of Venereal Diseases, 48, 65-68. 